\title{
Socio - Economic Benefits and the Associated Environmental Degradation Effects of Osyris lanceolata (Hochst \& Steudel) Utilization in Kitui County, Kenya
}

\author{
Mumbu Dominic Mutisya ${ }^{1^{*}}$, Muusya Mwinzi $^{1}$ and Kisangau Daniel Patrick ${ }^{2}$
}

${ }^{1}$ School of Environment, Water and Natural Resources Management, South Eastern Kenya University, P.O. Box 967 - 90200, Kitui, Kenya

${ }^{2}$ School of Pure and Applied Sciences, South Eastern Kenya University, P.O. Box 170 - 90200, Kitui, Kenya

* Corresponding author:

Telephone: +254724445406

Email: dominicmumbu@gmail.com;

DOI: $10.31364 / S C I R J / v 7 . i 4.2019 . P 0419628$

http://dx.doi.org/10.31364/SCIRJ/v7.i4.2019.P0419628

\begin{abstract}
The aim of this study was to assess the utilization and socio-economic benefits of Osyris lanceolata (The East African Sandalwood) in Kitui County, Kenya. Data was collected using questionnaires and analysed using SPSS version 20. A total of 120 respondents were interviewed. The results revealed that $78 \%$ of the respondents were aware of existence of $O$. lanceolata plants in their region. From these respondents there were two main uses of $O$. lanceolata wood products which included; medicinal and perfumery oil production. The main purpose of harvesting $O$. lanceolata was mainly for commercial use $(44.2 \%)$, with little use for domestic purposes $(16.7 \%)$. The major beneficiaries of $O$. lanceolata business were the manufacturers reported by $45 \%$ of the respondents, followed by middlemen as reported by $30 \%$ of the respondents. The least beneficiaries were the harvesters from the wild and the transporters reported by $17.5 \%$ and $5.8 \%$ of the respondents respectively. Majority of the respondents $(51.7 \%)$ reported that the main customers for $O$. lanceolata were the pharmaceutical companies followed by $29.2 \%$ who reported that it was perfume and cosmetic companies. There was significant Pearson correlation between socio-economic benefits $(\mathrm{r}=0.781, \mathrm{P}<0.01)$, usage knowledge $(\mathrm{r}=0.744, \mathrm{P}<0.01)$ and distribution $(\mathrm{r}=0.666 \mathrm{P}<0.01)$, with the harvesting trends of $O$. lanceolata from the wild. The study concluded that socio-economic benefits associated with $O$. lanceolata are contributing to its over-exploitation from the wild, thus calling for multifaceted interventions to minimize loss of this invaluable plant species from the wild.
\end{abstract}

Keywords: High value multipurpose plants, livelihoods, Conservation

\section{Introduction}

Osyris lanceolata (Hochst \& Steudel) (The East African Sandalwood) is a predominantly dry land shrub / tree species with Kenya as one of its major range states and especially in Kitui county and other arid and semi-arid areas. The species has also been documented to occur in Baringo, Narok, and Bomet counties among others. The tree is locally known as, Munyungamai, Ndonga or Kithawa in Kikamba, Msandali / Mti wa marashi (Swahili), Muthithi (Kikuyu), Mberegesa (Chagga), Olseyeayyesi (Maasai). Sandalwoods are 
also indigenous to India, Nepal, Bangladesh and Sri Lanka amongst other Indo - pacific Islands (Orwa et $a l ., 2009)$. In Kitui County, the tree has been recorded to grow in the central ridges, and on Mutonguni, Kyawea and Endau Hills (Kamondo et al., 2014).

O. lanceolate is an evergreen shrub in the family Santalaceae. It is a semi - parasitic shrub or small tree growing to a height of up to six meters. The species is dioecious with a given tree being either male or female. It is multi-stemmed with dark-brown to blackish bark. The species is evergreen with many drooping small branches with bluish to yellow-green, sharply pointed leaves. Sandalwood is a semi-parasite with its roots attaching to roots of host plants from which they absorb nutrients. The tree occurs on rocky ridges, mountain slopes and the margins of dry forests and in evergreen bush land, in grassland and in thickets. The tree grows at an altitude of between 900 - 2550m above sea level. Osyris belongs to the semi - parasitic plant family Santalaceae (the sandalwood family) and its roots will always be found associating with those of host plants (Mathenge et al., 2005). O. lanceolata is associated with other species such as Harrisonia abbysinica, Euclea divinivorum, Lantana camara, Cajanus cajan, Rhus natalensis, Rhus vulgaris, Maytenus acuminata, Carrisa edulis, Croton megalorcapus, Acacia kirkii, Grewia similis and Dodonaea viscosa amongst others (Kamondo et al., 2014).

The East African sandalwood is among the sandalwoods known for producing fragrance-scented wood and a world-famous essential oil used in various cosmetics and fragrance industries and has gained popularity also in medicine industries (Dwivedi et al., 1999).

Traditionally, the tree has different uses among different people in Kenya, including making of red dye, smoking milk containers, healing wounds and treating stomach ache, tonsils, diarrhoea, ulcers, snakebite and rashes. The demand for sandalwood has by far outstripped its supply (Krotz et al., 1994).

However, the nature of exploitation of $O$. lanceolate in Kitui County raises concern on its survival in the wild as it involves uprooting of the whole tree / shrub. The mode and scale of harvesting has made the tree to be locally endangered which threatens not only the survival of the species, but also the sustainability of the trade in the species products. O. lanceolata is harvested in the wild by uprooting the whole tree including its roots because the essential oil concentration is higher in the roots than the trunk (Mukonyi et al 2011). Under normal conditions, young trees grow slowly, only gradually developing a core of heartwood. It is reported that the harvesting methods used are highly destructive since the whole plant needs to be uprooted to get the roots, leading to a serious depletion of its populations. Unfortunately, while the resource base is declining, the markets of sandalwood oil and products have been rising (Kamondo et al., 2014).

The aim of this study was therefore to assess the utilization and socio - economic benefits of O. lanceolata and the associated environmental degradation impacts in Kitui County. 


\section{Materials and Methods}

\section{Description of the study area}

The study was carried out in Kitui County which is one of the 47 counties in the country located about 160 $\mathrm{km}$ east of Nairobi City. It is the sixth largest county in the country, covering an area of $30,496.4 \mathrm{~km}^{2}$ including 6,369 $\mathrm{km}^{2}$ occupied by Tsavo East National Park and Mwingi North Reserve. The county shares its borders with seven other counties namely Machakos and Makueni to the west, Tana River to the east and south - east, Taita Taveta to the south, Embu to the north - west and Tharaka - Nithi and Meru to the north. It is located between latitudes $0^{0} 10^{\prime}$ and $3^{\circ}$ south and longitudes $37^{\circ}$ and $39^{\circ} 0$ 'East. (GoK, 2013).

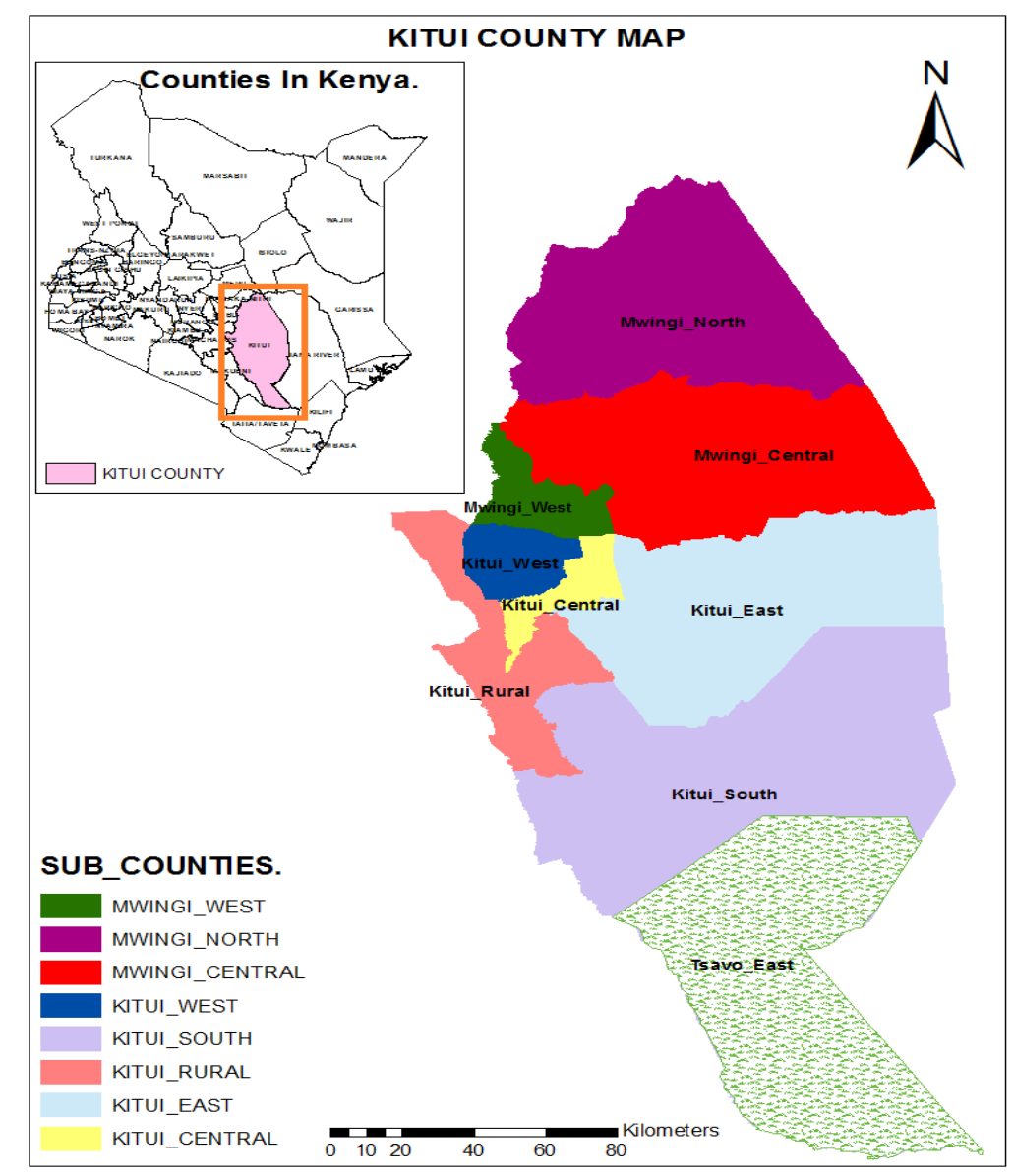

Figure 1: Position of Kitui County in Kenya

The study was carried out in four sub - counties of Kitui County namely Kitui South, Kitui East, Kitui West and Kitui Central. The general study area lies within Kitui County ranges and hills. 
Table 1: Details of location of the survey areas

\begin{tabular}{llll}
\hline S/No & Sub-County & Location & Sub-location \\
\hline 1 & Kitui East & Endau & Ndetani \\
& & & Kathua \\
& & & Kinanie \\
& & Mutomo & Katumbi \\
& Kitui South & & Kwala \\
& & & Kitoo \\
& & & Kandai \\
& Kitui West & Mutonguni & Kangondi \\
& & & Mithini \\
& & & Mutonguni \\
& & & Musengo \\
& Kitui Central & Mulango & Wikililye \\
& & & Kyangunga \\
& & & Wii \\
& & & Kyambiti \\
\hline
\end{tabular}

\section{Data collection}

Cluster sampling was used to select the sub - counties based on agro - ecological zones. Purposive sampling was used to select locations and sub - locations in each sub - county (Ranjit, 2011). Open and closed - ended household questionnaires, key informant questionnaires and Focused Group Discussions were used to gather information from the community and local experts working in Kitui County (Mugenda, 2011). Data was analysed for four sub - counties, namely Kitui Central, Kitui West, Kitui East and Kitui South. The respondents included the general community, local administrators (chiefs and their assistants) and herbalists considered as ethno- practitioners in this study. A total of 120 questionnaires were administered and filled in the field. In addition, a total of key informant 20 questionnaires were also administered to government departments and non-governmental organizations in the study area. The Geographical Information System (GIS) was used to analyse GPS data collected during the field exercise.

\section{Data analysis}

Data collected in the field was keyed into Statistical Package for Social Sciences (SPSS) version 20.0. Qualitative data generated from the open-ended research tools were organized into themes and patterns based on the study objectives and questions (Orodho, 2008). The organization of database into map layers provided rapid access to data elements required for geographic analysis. Tables, maps, plates and graphs were used to describe and summarize the data while the inferential statistics used for this study included Correlations, Model summary, Chi - square, ANOVA, multiple regression and coefficients. As part of the analysis, Pearson's Correlation Analysis was also done on the independent and the dependent variables. 


\section{Results}

On average, $(55.4 \%)$ of the respondents were males while $44.6 \%$ were females. At least $40 \%$ of the respondents were 30 - 39 years of age. This was followed by $40-49$ years with $30 \%$ respondents. Those above 50 years were $20 \%$. The least were those below 30 years with $16.7 \%$. On the education level of respondents, it was revealed that $46.7 \%$ of them had primary education as their highest level of education, followed by $23.3 \%$ with secondary education and $19.2 \%$ with no education at all. There were however some respondents with college and university education at $5.8 \%$ and $3.3 \%$ respectively.

The logistic regression analysis on socio - economic factors was found significant $(\mathrm{p}<0.05)$ in influencing the $O$. lanceolata utilization in the study areas: gender $(\mathrm{p}=0.017)$; level of education $(\mathrm{p}=0.042)$, and distribution of $O$. lanceolate $(\mathrm{p}=0.038)$. Other factors that were found insignificant $(\mathrm{p}>0.05)$ in influencing the $O$. lanceolata utilization in the study area were age $(\mathrm{p}=0.760)$, marital status $(\mathrm{p}=0.0821)$ and religion $(\mathrm{p}=0.0673)$. There was a significant Pearson correlation between gender $(\mathrm{r}=0.638, \mathrm{p}<0.01)$, level of education $(\mathrm{r}=0.728, \mathrm{p}<0.01)$ and household income sources $(\mathrm{r}=0.762, \mathrm{p}<0.01)$, with the harvesting and utilization trends of $O$. lanceolata from the wild.

Table 2: Demographic information of the respondents

\section{Research Parameters}

\begin{tabular}{|c|c|c|c|c|c|c|c|}
\hline \multirow[t]{4}{*}{$\mathrm{N}=120$} & & Kitui & Kitui East & Kitui & Kitui & Mean & Std. \\
\hline & & West & F (\%) & Central & South & F (\%) & deviation \\
\hline & & F $(\%)$ & $n=28$ & F $(\%)$ & F $(\%)$ & $\mathbf{n}=\mathbf{3 0}$ & \\
\hline & & $\mathrm{n}=\mathbf{3 0}$ & & $n=33$ & $n=29$ & & \\
\hline \multirow[t]{4}{*}{ Gender } & Male & $16(53.3)$ & 11(39.3) & $22(66.7)$ & $17(58.6)$ & $17(55.4$ & 0.617 \\
\hline & & & & & & ) & \\
\hline & Female & $14(46.7)$ & $10(35.7)$ & $18(54.5)$ & $14(41.6)$ & $13(44.6$ & 0.69 \\
\hline & & & & & & ) & \\
\hline \multirow[t]{6}{*}{ Age } & Below 30 & $7(23.3)$ & $3(10.7)$ & $4(12.1)$ & $5(17.2)$ & $5(16.7)$ & 0.25 \\
\hline & $30-39$ & $9(30.0)$ & $10(33.3)$ & $13(39.4)$ & $15(51.7)$ & $12(40.0$ & 0.479 \\
\hline & & & & & & ） & \\
\hline & $40-49$ & $8(26.7)$ & $11(39.3)$ & $12(36.4)$ & $9(31.0)$ & $10(30.0$ & 0.25 \\
\hline & & & & & & ) & \\
\hline & 50 & $4(13.3)$ & $5(17.9)$ & $6(18.2)$ & $8(27.6)$ & $6(20.0)$ & 0.375 \\
\hline
\end{tabular}


above

Level of

Primary

11(36.7) 10(35.7)

20(60.6)

15(51.7)

14(46.7 1.107

education

$\begin{array}{lcccccc}\text { Secondary } & 3(10.0) & 5(17.9) & 7(21.2) & 13(44.8) & 7(23.3) & 2.0 \\ \text { College/ } & 1(3.3) & 2(7.0) & 3(9.1) & 2(6.9) & 2(5.8) & 0.25 \\ \text { polytechnic } & & & & & & \\ \text { University } & 1(3.3) & 1(3.5) & 1(3.0) & 2(6.8) & 1(3.3) & 0.25 \\ \text { None } & 3(10.0) & 5(17.9) & 7(21.2) & 9(31.0) & 6(19.2) & 0.55\end{array}$

Marital status

Married

$18(60.0) \quad 20(71.4)$

25(75.8)

21(72.4)

$21(70.0 \quad 0.31$

)

$\begin{array}{lllllll}\text { Single } & 2(6.6) & 4(14.3) & 6(18.2) & 8(27.6) & 5(17.5) & 0.85\end{array}$

Religion

Divorced/
Separated

$3(10.0) \quad 4(14.3) \quad 2(6.1)$

$6(20.7)$

$4(12.5) \quad 0.56$

$\begin{array}{lllllll}\text { Catholic } & 5(16.7) & 8(28.6) & 13(39.4) & 18(62.1) & 11(36.7 & 2.45\end{array}$

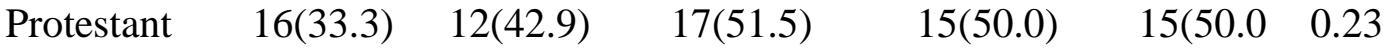

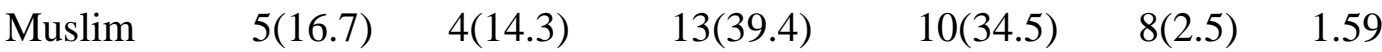

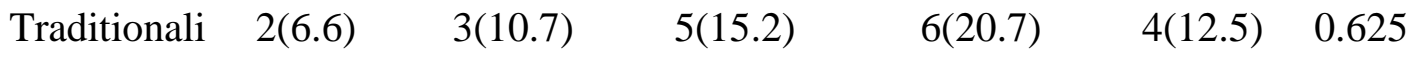

st

\section{Awareness and occurrence of $\boldsymbol{O}$. lanceolata in Kitui County}

Most of the respondents interviewed (78\%) were aware of the O. lanceolata plant material species, against $22 \%$ who were not aware. Majority of the respondents $64 \%$ reported that it was a taboo to use O. lanceolata for firewood against $36 \%$ who reported otherwise.

On existence of $O$. lanceolata, it was established that Kitui South Sub - County had slightly more $(65.5 \%)$ people aware of the existence of $O$. lanceolata plant materials compared to other Sub-counties. Most of the land where $O$. lanceolata was growing was owned by individuals. Kitui South Sub - County had more land ownership with $68.7 \%$ compared to other sub - counties $(\mathrm{p}<0.05)$. It was also found that Kitui East subcounty had slightly more registered self-help conservation groups with 53.6\% compared to other Sub- 
counties $(\mathrm{p}<0.05)$. More of the respondents $(57.1 \%)$ in Kitui West than in any other subcounty were trained on $O$. lanceolata propagation techniques $(\mathrm{p}<0.05)$.

Awareness on $O$. lanceolata existence was most statistically significant in Kitui Central, Kitui West and Kitui South Sub - Counties $(\mathrm{p}<0.05)$. Chi - square analysis showed that there was strong relationship between awareness and harvesting of $O$. lanceolata in the study area. There was a significant Pearson correlation between usage knowledge $(r=0.744, \mathrm{p}<0.01)$ with the harvesting trends of $O$. lanceolata from the wild.

Table 3: Community awareness on existence of $\boldsymbol{O}$. lanceolata plant species

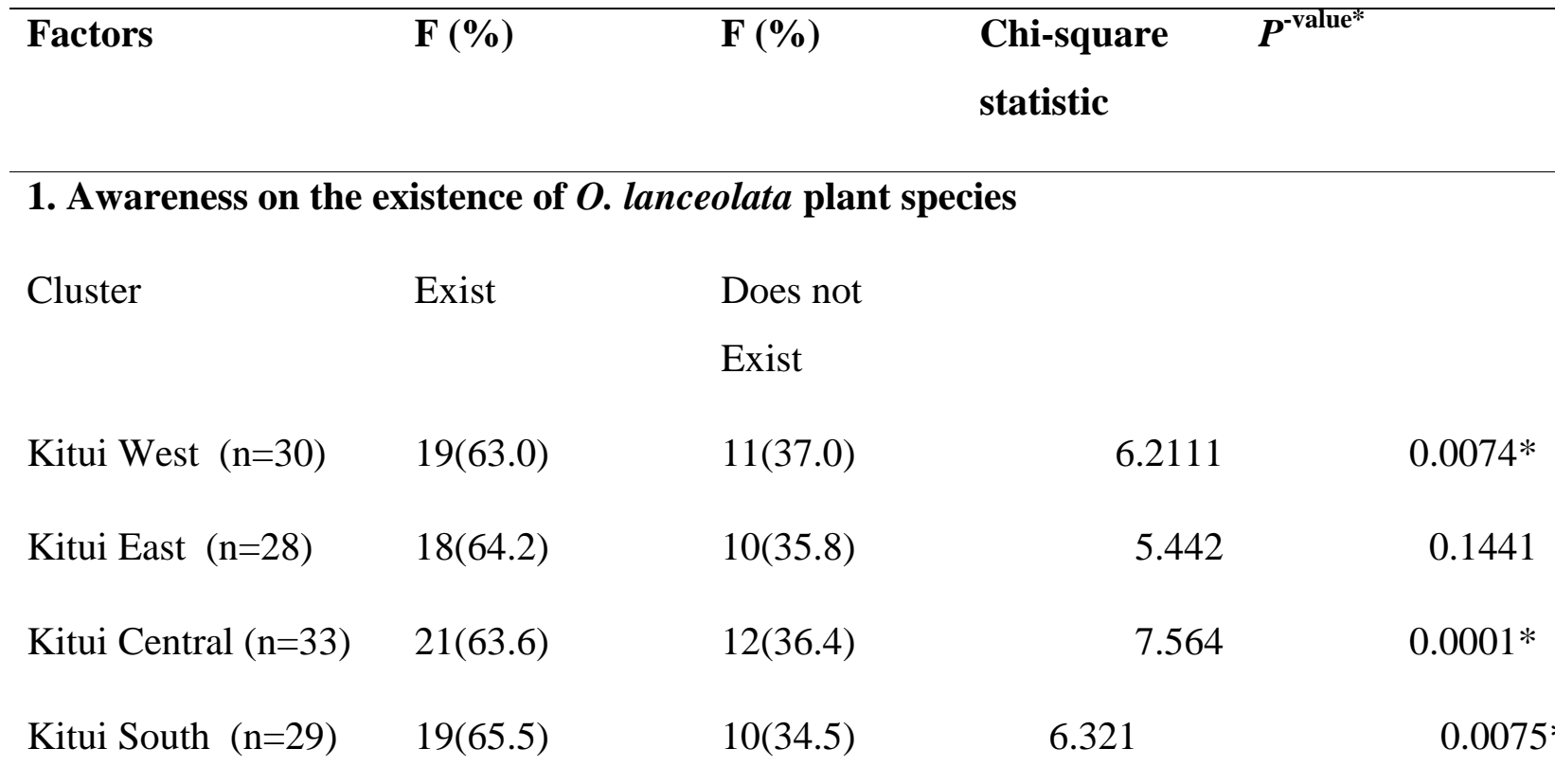

\section{Ownership of land where $O$. lanceolata grows}

Cluster Own Not own

$\begin{array}{lcccc}\text { Kitui West }(\mathrm{n}=30) & 17(56.7) & 13(43.3) & 8.104 & 0.0001^{*} \\ \text { Kitui East }(\mathrm{n}=28) & 16(57.1) & 12(42.9) & 7.221 & 0.3411 \\ \text { Kitui Central }(\mathrm{n}=33) & 18(54.5) & 15(46.5) & 5.497 & 0.2487 \\ \text { Kitui South }(\mathrm{n}=29) & 20(68.9) & 9(31.0) & 6.223 & 0.002^{*}\end{array}$

\section{Existence of organized community groups}

Cluster

Exist

Does not

Exist

Kitui West $(n=30) \quad 13(43.3)$

$17(56.7)$

9.314

$0.0002 *$ 


$\begin{array}{lcccc}\text { Kitui East }(\mathrm{n}=28) & 15(53.6) & 13(56.4) & 7.2584 & 0.0002 * \\ \text { Kitui Central }(\mathrm{n}=33) & 10(30.3) & 23(69.7) & 5.3321 & 0.0004 * \\ \text { Kitui South }(\mathrm{n}=29) & 8(27.6) & 21(72.4) & 6.2475 & 0.0001 *\end{array}$

\section{Training on $O$. lanceolate utilization}

$\begin{array}{lcccc}\text { Cluster } & \text { Trained } & \text { Not trained } & 8.365 & 0.1451 \\ \text { Kitui West }(\mathrm{n}=30) & 16(57.1) & 14(42.9) & 5.172 & 0.0047^{*} \\ \text { Kitui East }(\mathrm{n}=28) & 12(46.7) & 16(53.3) & 8.214 & 0.2254 \\ \text { Kitui Central }(\mathrm{n}=33) & 14(42.4) & 19(57.6) & 6.387 & 0.0224 \\ \text { Kitui South }(\mathrm{n}=29) & 13(44.8) & 16(55.2) & 4.215 & 0.8552\end{array}$

*Significant level at 0.05; frequencies $(\mathrm{F}),(\mathrm{n})$ represents respondents

\section{O. lanceolata growing habitats and ecosystems}

Majority of the respondents (38.3\%) indicated that $O$. lanceolate grew in the forests followed by $26.7 \%$ who indicated that it grew on the hill tops. Also $19.2 \%$ indicated that it grew on rocky areas while $10.8 \%$ indicated that the species grew on farmland. The least was $5 \%$ who indicated that it grew along rivers (Figure 2).

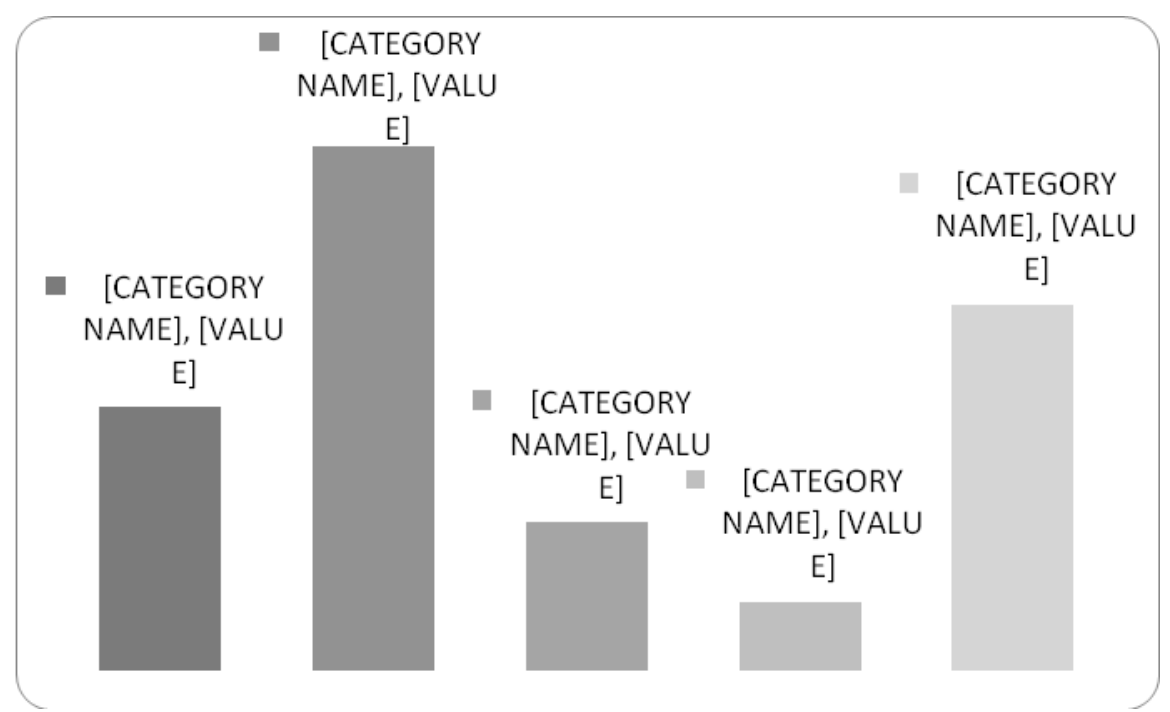

Figure 2: $O$. lanceolata growing habitats and ecosystems

\section{Distribution of $O$. lanceolata in the targeted Sub - Counties}

The actual areas where $O$. lanceolata was found growing in Kitui West Sub - County were Kavonge, Kwa Mbelu, Muthale and Musengo. In Kitui East Sub - County the O. lanceolata plant species was plenty at Endau Hills while in Kitui Central Sub - County, the plant grows in Wikililye, Chuluni, Kavalula, 
Nzambani and Kyanika. In Kitui South Sub - County, the plant grows at Ikanga, Kyatune, Mutha hills and in Mutomo. Figure 3 shows distribution of $O$. lanceolata within the targeted study areas.

There was a significant Pearson correlation between distribution $(\mathrm{r}=0.666 \mathrm{p}<0.01)$, with the harvesting trends of $O$. lanceolata from the wild.

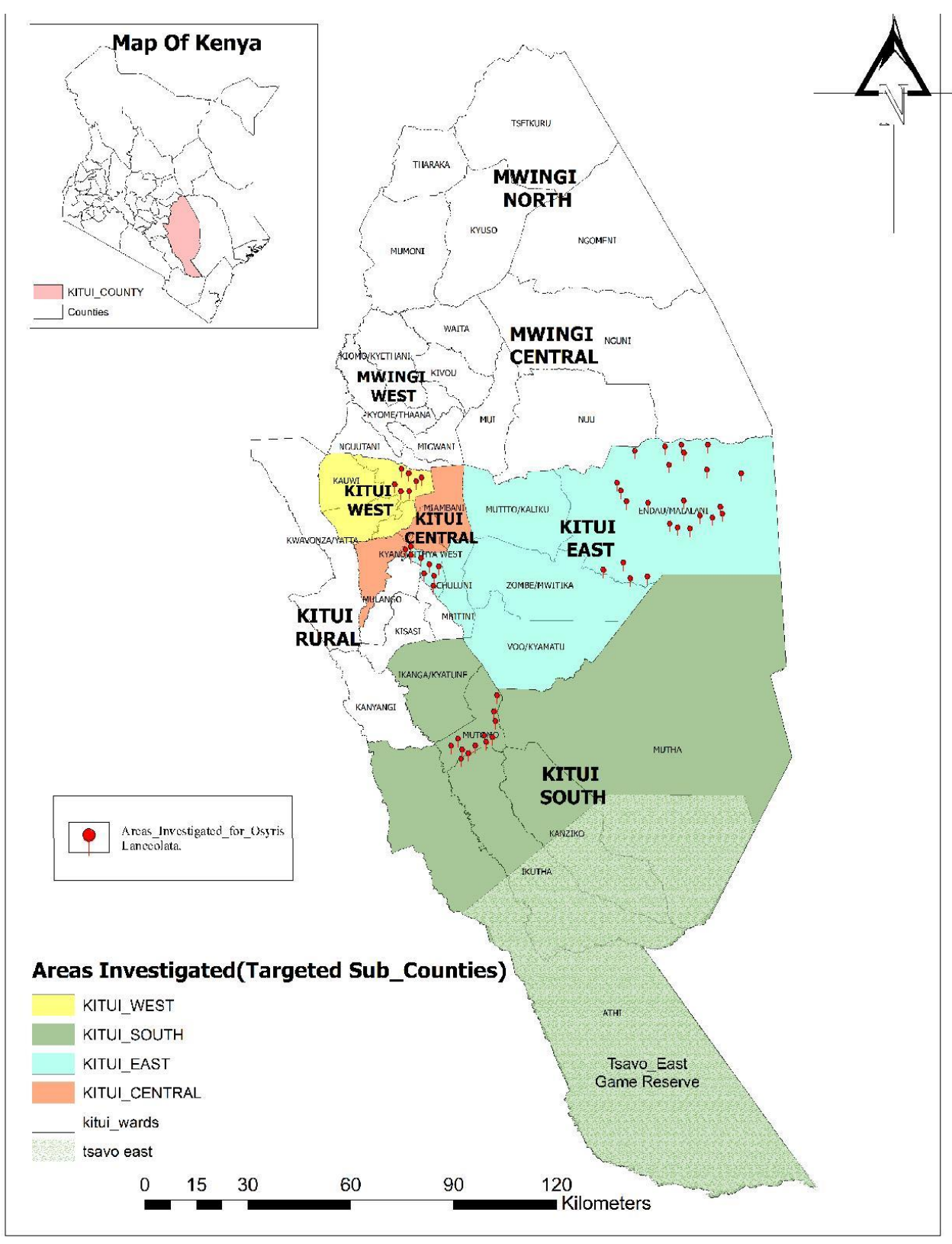

Figure 3: Map showing the distribution of $O$. lanceolata in the targeted study sub - counties in Kitui County

\section{Assessment of the socio - economic benefits of $O$. lanceolate utilization in Kitui County}

The logistic regression analysis on the following socio - economic related factors were found significant ( $\mathrm{p}$ $<0.05)$ in influencing the $O$. lanceolata utilization in the study area: household income sources $(\mathrm{p}=0.036)$; land sizes $(\mathrm{p}=0.047)$. There was a significant Pearson correlation between household income sources $(\mathrm{r}=$ $0.762, \mathrm{p}<0.01$ ), with the harvesting and utilization trends of $O$. lanceolata from the wild. 
The main purpose for harvesting $O$. lanceolate was for income and commercial purposes (44.2\%), followed by $39.2 \%$ for both commercial and local use, while local use only was by $16.7 \%$ of the respondents. However, there was substantial level of illegal harvesting of $O$. lanceolata material from the wild (Plate 1). In Kitui County, incidences of illegal poaching of $O$. lanceolata have been reported for the last three years due to the demand of the plant as raw material for the manufacturing companies. The major beneficiaries of $O$. lanceolata business were the manufacturers (45\%) followed by the middlemen (30\%). The local harvesters only benefited by $17.5 \%$ while the transporters benefited by $5.8 \%$ (Figure 4).

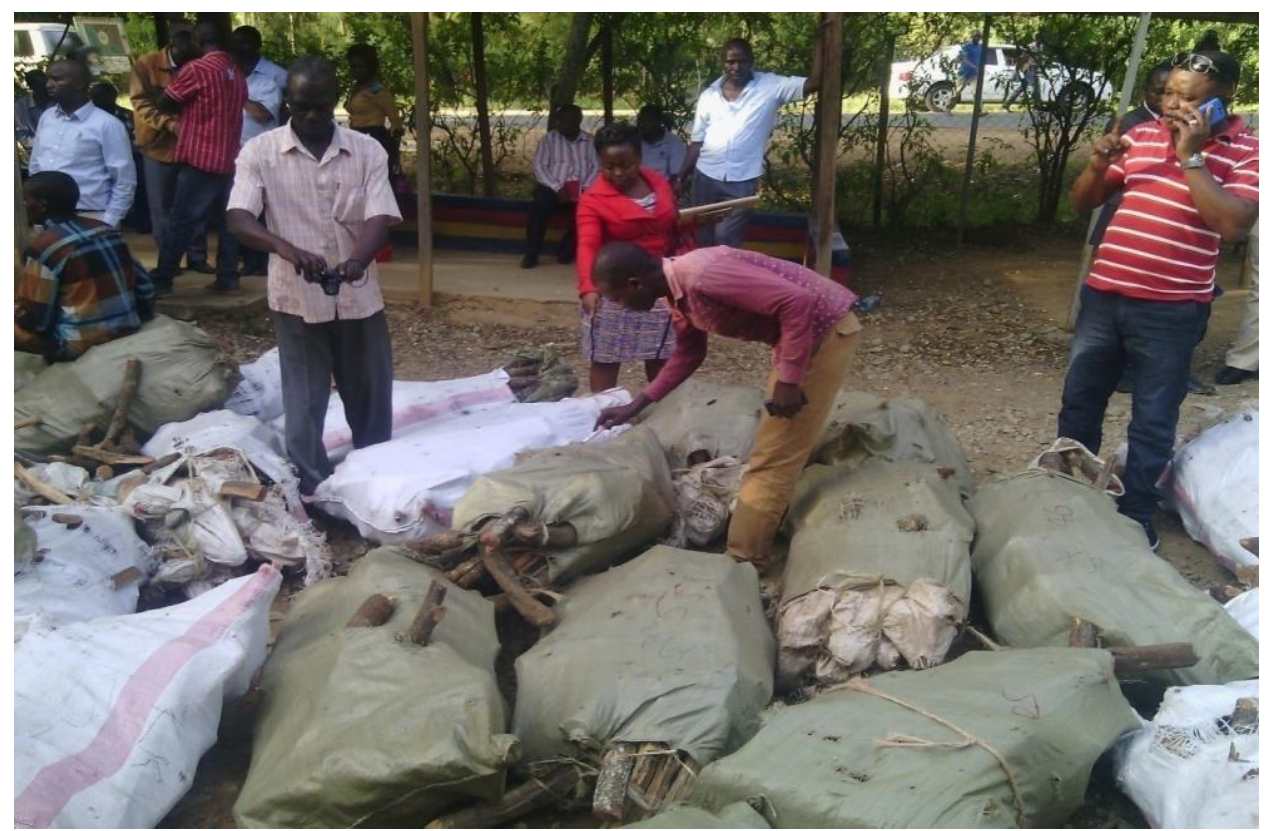

Plate 1: Confiscated bags of illegally harvested $O$. lanceolate roots and stems at Kitui Police station

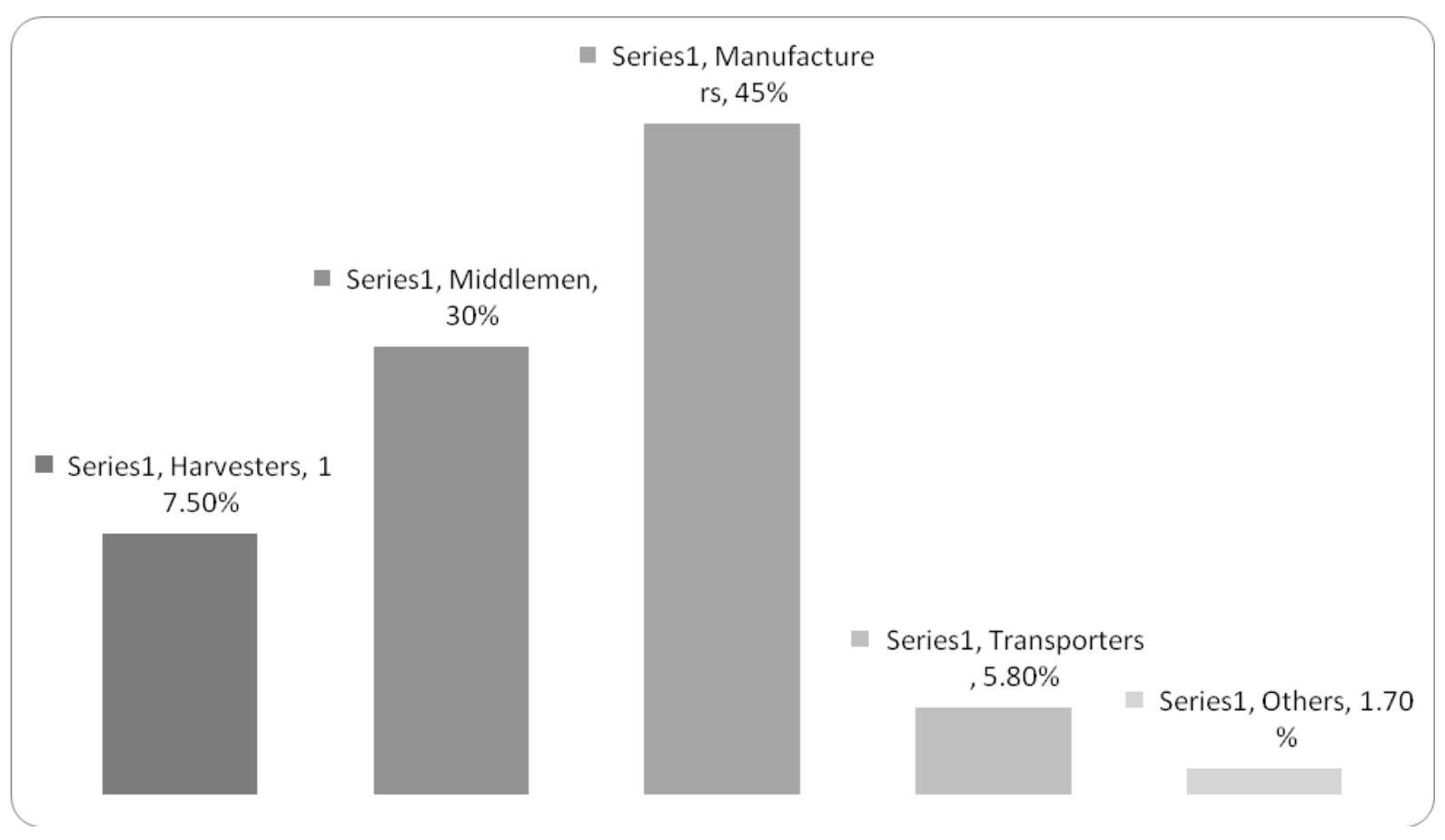

Figure 4: Graph showing $O$. lanceolate plant business beneficiaries 
Majority of the respondents $(48.3 \%)$ reported that they had harvested $O$. lanceolate for less than one year. This was followed by those who had harvested the plant material for a duration ranging between $2-4$ years (26.7\%). Those who had harvested the plant material for a period ranging between $5-7 \%$ were $14.2 \%$ and those who had harvested it for more than 7 years were $10.8 \%$.

\section{Factors that determine selling price for $\boldsymbol{O}$. lanceolata products}

Selling price for $O$. lanceolate was mainly determined by the buyers $(51.7 \%)$, followed by $23.3 \%$ of the respondents who indicated that it was determined by the market forces. The respondents who indicated that the selling price of the plant material was determined by the seasons and self were $19.2 \%$ and $5.8 \%$ respectively.

The study established that one litre of the refined and processed $O$. lanceolata oil price ranges between Kshs. 80,000 to Kshs. 100,000. Majority of the respondents (51.7\%) reported that the main customers for $O$. lanceolate were the pharmaceutical companies followed by perfume cosmetics companies at 29.2\% (Table 4).

Table 4: Main customers of $O$. lanceolata products

Frequency Percent

Pharmaceutical companies

Perfume cosmetics

Food industry

Clothing

Middlemen

62

18

51.7

29.2

15.0

Total

120

100.0

Most of the respondents (64.2\%) indicated that the plant material was being used for medicinal purposes, followed by the oil production at $25.8 \%$. Construction, wood carving and firewood utilization were least reported at $1.7 \%, 2.5 \%$ and $5.0 \%$ respectively (Figure 5). 


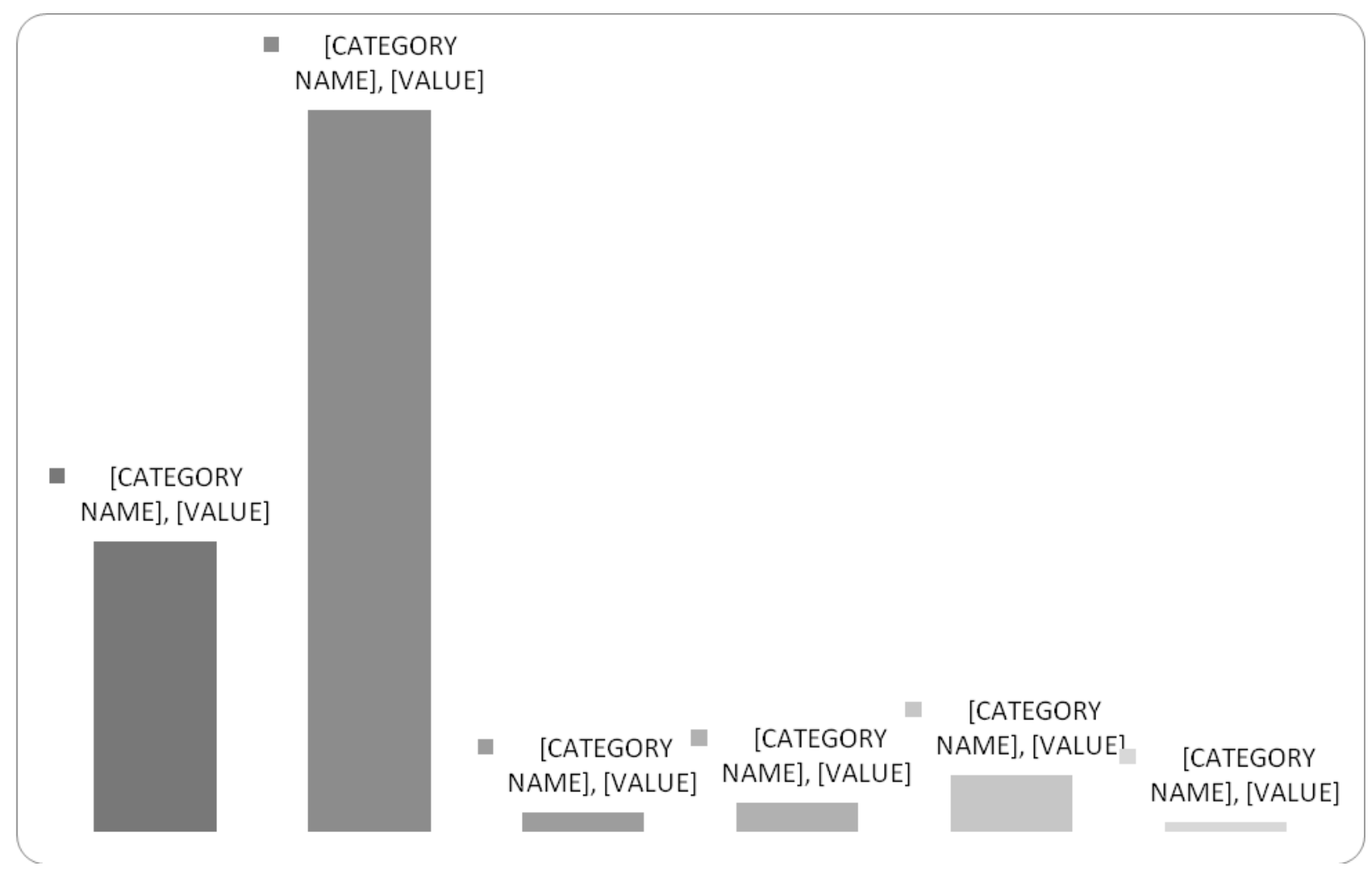

Figure 5: Graph showing O. lanceolate major uses

Methods of harvesting $O$. lanceolata

Majority of the respondents $(73.3 \%)$ reported that the main method for harvesting $O$. lanceolate was by total uprooting. Other methods of harvesting included selective and branch harvesting each at $10.8 \%$, debarking $(3.3 \%)$ and leaf harvesting $(1.7 \%)$. Majority of the respondents $(42.5 \%)$ reported that the roots were the most harvested parts of the plant material, followed by both stem and roots (25\%), stem (18.3\%), leaves $9.2 \%$ and branches $5.0 \%$ (Table 5).

Table 5: Methods used in harvesting $O$. lanceolata

Total uprooting

Selective harvesting

Branch harvesting

Debarking

Leaf harvesting 
Majority (42.5\%) of the respondents indicated that the part of the $O$. lanceolata plant harvested is the roots. This was followed by those who indicated that it's both stem and roots $(25 \%)$. Others indicated that it was stem $(18.3 \%)$, leaves $(9.2 \%)$ and branches $(5 \%)$.

The researcher further sought to establish the environmental degradation consequences caused by over exploitation of sandalwood plant. The responses were presented in table 6 .

\section{Major environmental degradation effects}

Majority of the respondents (55\%) reported that the major environmental degradation consequences caused by over - exploitation of $O$. lanceolata plant materials was increased soil erosion. This was followed by the drop in crop production (29.2\%), lack of fodder for livestock (8.3\%) and diminishing of water resources (7.5\%) (Table 6).

Table 6: Environmental degradation consequences caused by exploitation of $O$. lanceolata

\section{Frequency $\quad$ Percent}

$\begin{array}{lcc}\text { Drop in crop production } & 35 & 29.2 \\ \text { Increased soil erosion } & 66 & 55.0 \\ \begin{array}{l}\text { Lack of fodder for } \\ \text { livestock }\end{array} & 10 & 8.3 \\ \text { Diminishing of water } & 9 & 7.5 \\ \text { resources } & & \end{array}$

\section{Discussion}

Gender was found to be a significant factor in determining awareness and utilization of $O$. lanceolate utilization in the study area $(\mathrm{p}<0.05)$. More males were aware and involved in O. lanceolata utilization than females as similarly observed by Helmstadler, (2009), who found that more males than females participated in the harvesting of the O. lanceolata plant products. Ochanda, (2011) also showed that most of $O$. lanceolata was poached at night due to high demand for the manufacturers of pharmaceutical and cosmetic products. Most of the respondents had basic education and low income levels. The respondents' main source of income was subsistence farming which included crop farming, livestock husbandry and bee keeping. These findings were also confirmed by Nyerere (2000) who reported that most of the rural communities depend on agricultural farming and animal husbandry as their main sources for livelihoods. The low production levels revealed in the results mean that respondents could have experienced regular crop 
failures, frequent livestock deaths due to lack of the pastures and thus they could have resulted to $O$. lanceolata harvesting as an alternative source of livelihood. Similar findings were confirmed by Beentje (1994) who reported that in most cases where communities neighbour natural resources, they tend to exploit those resources and especially when they do not have alternative sources of income. The F-statistics at $(\mathrm{F}=$ 74.619) revealed statistically significant relationship between $O$. lanceolata harvesting and socio economic variables including level of education, age, income levels and usage knowledge of the $O$. lanceolata, occupation and land size of the respondents $(\mathrm{p}<0.05)$.

Most of the respondents were married and aged between 30 - 39 years, meaning that majority were in the most productive age bracket. This was confirmed by Helmstadler, (2009) who established that most of the natural resources are exploited by the younger generations than the older generations. Due to lack of formal employment most of the respondents could have turned to the harvesting and trading of $O$. lanceolata as a means to raising alternative incomes to sustain their families. The study established that $O$. lanceolate had been known for a long time but apart from the use as firewood and medicine, no other uses were known to the community until the last few decades. This could have been due to the rise in demand of the $O$. lanceolata products in the pharmaceutical and cosmetic industry as reported by Machua et al., (2009). According to them, massive exploitation of $O$. lanceolata started in Tanzania and when $O$. lanceolata populations became too few, the exploitation spilled over to Kenya through Mt. Kilimanjaro area, Chyulu hills and other regions.

As documented by Machua et al., (2009) much of the distribution of $O$. lanceolate was found to occur in dry land forests, stony and rocky areas. This shows that cultivating the tree in the study area could be an appropriate alternative given that most of the ASALs where $O$. lanceolata grows are characterized by either unreliable rainfall or poor unproductive soils as a result of continuous soil erosion. Since most of the people interviewed were aware of the occurrence of $O$. lanceolata, it becomes easy to institute sustainable conservation measures of the plant. In some places like Mutha, a number of respondents seemed not to be very familiar with $O$. lanceolata plant. However, they were aware of the other plant species that are closely associated with the plant, especially the medicinal ones. These findings were confirmed by Mukonyi et al, (2011) who found out that most of the rural populations in Kenya depend on the herbal medicine derived from the world. It was established that most of the $O$. lanceolate plant material grew on communal forests and individual farmlands and this makes it difficult to conserve and protect the plant. This was documented by KFS, (2010) who reported that most of exploitations and unsustainable harvesting of both woody and non-forest forest products occur in the non - gazetted and unprotected areas. In Kitui East sub - county, $O$. lanceolata growing was observed at Endau hills which is a government gazetted forest. Communities indicated that they have not been involved by the government agencies in the protection and conservation of the tree species. In Kitui Central and Kitui West Sub - Counties, the plant species grew on individual 
farmlands and this made enforcement difficulty to effect. In Kitui South Sub - County, the plant was found to grow in community forests and thus the reason why there has been rampant poaching of the O. lanceolata materials and products in the area. There exist challenges on the charges for culprits arrested in possession of illegal $O$. lanceolata materials. There are no clear guidelines in Kenya on how to promote in - situ conservation of $O$. lanceolata either through the domestication of the plant species or by any other means. The price of the $O$. lanceolata products has not been established and thus leading to exploitation of the farmers by the middlemen. In Kitui Central, it was reported that the council of elders discouraged the use of the plant material for firewood because it produced an awful smelling smoke. This traditional belief helped to conserve the plant species from unsustainable exploitation from the wild. During this study, it was found that there were no established community groups or guidelines dealing with the conservation and utilization of $O$. lanceolata. However, most of the respondents were aware of the harvesting of the plant species from the wild. Machua et al., (2009) documented that the major mode of harvesting of the plant was uprooting the whole tree hence seriously interfering with its natural regeneration.

A study in the Chyulu Hills in Kenya showed that locals used O. lanceolata for commercial and medicinal purposes for the treatment of both animals and people such as snake bites (Ochanda, 2011). Due to illegal harvesting, most of the mature trees have been removed from the wild. Attempts at local nursery propagation have been unsuccessful. According to a report by a government taskforce on the harvesting and trade of $O$. lanceolata in Kenya, it was reported that poverty in the areas where the species occurs was the underlying factor that made the fight against the illegal trade of the plant difficult to win (KFS, 2010). Communities around Chyulu National Park earned Kshs. 4.00 to Kshs. 7.00 for every kilo of O. lanceolate harvested, of which the middlemen sold at Kshs. 80.00 per kilo. In the international market, it had been estimated that one litre of the refined and processed $O$. lanceolata oil sells at about Kshs.80, $000.00-$ 100,000.00 (Walker, 2006). Mathenge et al., (2005) recorded that wood of O. lanceolata is exported to China and India for processing. Processed products were exported to Indonesia, India, South Africa, France, Germany and eastern Asia countries for the cosmetic and pharmaceutical industry. Successful intervention measures therefore required to address poverty and alternative livelihoods (KFS, 2009). Most of the people were involved in the harvesting of the O. lanceolata mainly for commercial reasons and respondents felt that it was the manufacturers and middlemen who benefited in the whole value chain. This was so because farmers and local communities who are involved in the harvesting of the plant material did not have skills on where the harvested materials were taken to for more processing. It was observed that commercial harvesting of $O$. lanceolate was fairly a recent activity to the local community and therefore sale prices were mainly determined by the buyers and not by the wild harvesters. The main traded products of O. lanceolate included aromatic oils extracted from the heartwood, timber for handicrafts and sawdust for making incense. Heartwood of the trunk, branches and roots contain the essential oils, with highest concentrations in the 
roots. The essential oil is used in perfumery, pharmaceutical, religious and medicinal practices. The East African Sandalwood oil has been found to be one of the best essential oil in the world (Machua et al., 2009).

The main method used for $O$. lanceolata harvesting was by use of total root uprooting which caused severe environmental degradation as confirmed in the areas where O. lanceolata was mainly found (Ochanda, 2011). In Kenya, the species was protected by Legal Notice No. 3176 under the Forests Act, 2005 which gave protection to the species for a period of five years in order to allow for the development of sustainable harvesting mechanisms (GoK, 2007). Further, the species exploitation is regulated by the Wildlife Management Act Cap. 376, Environment and Management Coordination Act, (amended, 2015) and the Constitution of Kenya, 2010.

During the study, it was found that the main environmental degradation effect associated with unsustainable harvesting of $O$. lanceolata was degradation of water catchment areas. This in turn has caused increased surface run - off, flash flooding, reduced infiltration and increased soil erosion and siltation of the existing water harvesting structures. This was confirmed by Kieti et al, (2016) who reported that once watershed and catchment ecosystems are interfered with, they cease to supply essential ecological goods and services. Furthermore, these factors have threatened the hydrological functioning of forests - water interaction (Chene, 2005). The roots were the most preferred parts with the stems and branches being utilized as source of firewood. Once the roots of a plant are uprooted it means that the soil particles cannot be held together and this exposes the soil to agents of soil erosion FAO, (2015). Other environmental degradation effects reported were drop in crop production and lack of fodder for livestock as also confirmed by (FAO 2015). These occur due to loss of soil fertility whereby once active soil ingredients are washed away, the soil is left bare without sufficient nutrients to support crop production and fodder growth for livestock as similarly reported by Mary (2015).

All the independent variables such as $O$. lanceolata distribution, knowledge on usage, socio - economic benefits and environmental impacts had a positive correlation with the dependent variable, with $(\mathrm{r}=0.781$, $\mathrm{p}<0.01), \quad(\mathrm{r}=0.744, \mathrm{p}<0.01), \quad(\mathrm{r}=0.666 \mathrm{p}<0.01)$, and $(\mathrm{r}=0.581, \mathrm{p}<0.01)$ for socio - economic benefits, knowledge, distribution and environmental impacts respectively. According to Murray et al., (1999) there was statistically significant relationship between distribution of $O$. lanceolata, usage knowledge, socioeconomic benefits, and environmental impact and the harvesting of $O$. lanceolate from the wild. The regression model on harvesting of $O$. lanceolata $=1.04+0.207 \mathrm{x}_{1}+0.431 \mathrm{x}_{2}+0.641 \mathrm{x}_{3}-0.129 \mathrm{x}_{4}$ showed that the socio - economic benefit $\left(\mathrm{x}_{3}\right)$ had the highest contribution to the model $(0.641)$. This means that a unit change in socio - economic benefit would change the $O$. lanceolata harvesting by a factor of 0.641 . This was followed by usage knowledge and distribution with a factor of 0.431 and 0.207 respectively. It was however found that the change in environmental impact had a negative impact on the $O$. lanceolata (- 
0.129). These findings were supported by Mary (2015), who established that socio - economic benefits of harvesting $O$. lanceolata contributed highly to its exploitation due to high demand in the market.

\section{Conclusion}

In this study, it was established that most of the community members interviewed had received either formal or informal education. Those who had not received any form of education did not know the uses of the $O$. lanceolata. Most people harvested the plant material in order to earn an income. The major beneficiaries in the entire value chain were the manufacturers, middlemen and traders. Majority of the people involved in the harvesting of $O$. lanceolata did not have the necessary skills on how the material should be processed. Pharmaceutical and cosmetic companies were the main buyers of the O. lanceolata plant materials. Middlemen and manufacturers determined the selling and buying price of the $O$. lanceolata products. Majority of the people interviewed stated that they had been involved in the business of $O$. lanceolata business for less than a year and this meant that it was a new business to them. The major environmental degradation impact associated with $O$. lanceolata utilization was the increased soil erosion due to the uprooting of the whole plant as the dominant method of harvesting. There is need to put in place sustainable conservation measures and operational regulatory framework to control harvesting of this threatened, yet commercially viable plant species from the wild.

\section{Acknowledgements}

Funds to carry out this work were provided by the County Government of Kitui for which we are grateful. We are highly grateful to all respondents who participated in this study and to the both the Local and National Government administrators for their cooperation during the study period.

\section{References}

1. Beentje H. (1994). Description and ecology of some 1850 woody species indigenous to Kenya or that have been naturalized. Kenya Trees, Shrubs and Lianas. National Museums of Kenya. P 44 48.

2. Chene J. M. (2005). "Integrated Water Resources Management: Theory versus Practice. National Resources Forum 33, No.1 (February, 2005): 2 - 5.

3. Dwivedi C. and Ahang Y. (1999). Sandalwood oil prevents skin tumour development in CD1 mice. Eur J Cancer Prev. 8 (5): 449-455. doi:10.1097/00008469-199910000-00011. PMID 10548401.

4. FAO (2015). Global Forest Resources Assessment 2015.Kenya Country Report. Retrieved March, 2016, http://www.fao.org/documents/Card/en/c/8017d9cc-dcba-4484-a053-7851ab3c2ccb/.

5. GoK, (2009). Kenya National Bureau of Statistics, 2009 Population Census Report.

6. GoK (2013). Kitui County Integrated Development Plan (CIDP, 2013 - 2017) pages 4 - 44.

7. Helmstadter, G.C. (2009), Research Concepts in Human Behaviour Education, Psychology and Sociology, New York. 
8. Kamondo B., Giathi G., Osore C., Machua J., Kagunyu L., Wafula A., Bala P., Njuguna J., Wakori S., Maingi F., and Nyingi K. (2014). Growing East African Sandalwood guidelines for tree growers, Kenya Forestry Research Institute (KEFRI). Pg. 21 - 23.

9. Kenya Forests Service (2010). Challenges of conserving Sandalwood http://kenyaforests.blogspot.co.uk/2010/02/challenges-of-conserving-sandalwood.html retrieved in 2010.

10. Kenya Forests Service (2009). Perfumery sends Sandalwood numbers down. http://kenyaforests.wildlifedirect.org/2009/02/02/perfumery-sends-sandalwood-numbers-down retrieved in 2009.

11. Kieti R. N., Kauti M. K. and Kisangau D. K. (2016). Household Livelihood Strategies and Socio Economic Conditions Influencing Watershed Degradation in Kaiti Sub - watershed, Makueni County, Kenya.

12. Krotz A. and Helmchen G. (1994). Total Syntheses, Optical Rotations and Fragrance Properties of Sandalwood Constituents: $(-)-(Z)-$ and $(-)-(E)-\beta$-Santalol and their enantiomers, ent- $\beta$-Santalene. $601-609$.

13. Machua J., Kamondo B., Mwangi L., Gitehi G., and Chahilu O. (2009). Propagation of Osyris lanceolata (East Africa Sandalwood). Recent advances in forestry research for environmental conservation, improved livelihood and economic development. Proceedings of the $4^{\text {th }}$ KEFRI Scientific Conference, KEFRI Headquarters, Muguga, Kenya held between $6^{\text {th }}-9^{\text {th }}$ November, 2008.

14. Mary W. G. (2015). Biophysical Environmental Factors Influencing the Distribution and Yield of Osyris lanceolata (Hochst \& Steud): Case Study of Gachuthi and Kibwezi Forest, Kenya. Research journal pg. $45-49$.

15. Mathenge J, Kimini C.N.T. and Kamau P. (2005). Preliminary survey on the exploitation of East African Sandalwood (Osyris lanceolata) in South region of Kajiado and neighboring districts. Research journal pg. $25-27$.

16. Mugenda G. (2011). Social Science Research: Theory and Principles, Nairobi.

17. Mukonyi K.W. Kyalo S., LubiaI.K., Leitoro, E. MbakaR.M., Lusweti A.M. and Mutwiri F. M. (2011). Status of Osyris lanceolata in Kenya. Kenya Wildlife Service Report. 54 - 57.

18. Murray R. S. and Larry J. S. (1999). Statistics ( ${ }^{\text {rd }}$ Ed.); McGraw - Hill International editions; Schaums outline of theory and problems of statistics.

19. Nyerere, M. K. 2000, The African Socialism; leadership lessons (Revised, 2000) East Africa Publishing House, Nairobi, Kenya, pp.12-144. 
20. Ochanda, K.V. (2011). Conservation and management of Sandalwood tree (Osyris lanceolata, Hochst and Steudel) in Chyulu Hills, Kibwezi District, Kenya. Proceedings of the $5^{\text {th }}$ Annual Foresters Scientific Conference held between 24th $-26^{\text {th }}, 2010$.

21. Orodho, J. A. (2008). Techniques of writing Research Proposal and Reports in Education and social Sciences. Kenya.

22. Orwa, C., Mutua. Kindt R., Jamnadass R., and Simons A. (2009). Agroforestry Database: a tree $\begin{array}{lllll}\text { reference } & \text { and } & \text { guide } & \text { version } & 4.0\end{array}$ http://www.worldagroforestry.org/treeb2/AFTPDFS/Osyrislanceolata.pdf. 2009.

23. Ranjit K. (2011). Research methodology: A step-by-step guide for beginners. Sage; Los Angeles. 